\title{
Dual therapy based on raltegravir and boosted protease inhibitors - the experience of Polish centers
}

\author{
Elżbieta Jabłonowska ${ }^{1}$, Piotr Pulik², Anna Kalinowska ${ }^{3}$, Jacek Gąsiorowski ${ }^{4}$, Miłosz Parczewski ${ }^{5}$, \\ Monika Bociąga-Jasik², Elżbieta Mularska ${ }^{6}$, Łukasz Pulik², Ewa Siwak², Kamila Wójcik ${ }^{1}$
}

\begin{abstract}
${ }^{1}$ Clinic of Infectious Diseases and Hepatology, Medical University of Lodz, Lodz, Poland ${ }^{2}$ Hospital for Infectious Diseases, HIV Out-Patient Clinic, Warsaw, Poland ${ }^{3}$ Department of Infectious Diseases, Jagiellonian University Medical College, Krakow, Poland

${ }^{4}$ Department of Infectious Diseases, Hepatology and Acquired Immune Deficiencies, Wroclaw Medical University, Wroclaw, Poland

${ }^{5}$ Department of Infectious and Tropical Diseases and Immune Deficiency, Pomeranian Medical University, Szczecin, Poland

${ }^{6}$ Outpatient Clinic for AIDS Diagnostics and Therapy Specialistic Hospital, Chorzow, Poland
\end{abstract}

Submitted: 23 April 2016

Accepted: 3 July 2016

Arch Med Sci 2018; 14, 4: 860-864

DOI: https://doi.org/10.5114/aoms.2016.62445

Copyright @ 2016 Termedia \& Banach

\section{Abstract}

Introduction: The aim of the study was to present the experience of Polish centers regarding dual therapy based on the integrase inhibitor raltegra$\operatorname{vir}(\mathrm{RAL})$ and ritonavir-boosted protease inhibitors $(\mathrm{PI} / \mathrm{r})$ for treating treatment-naïve and -experienced HIV-infected patients.

Material and methods: The paper concerns a retrospective multicenter study. The medical databases of six main Polish HIV centers from January 2009 to December 2014 were analyzed for the use of combined antiretroviral treatment consisting of RAL $+\mathrm{PI} / \mathrm{r}$. This study included $126 \mathrm{HIV}$-infected patients receiving $\mathrm{RAL}+\mathrm{PI} / \mathrm{r}$ therapy, of whom 17 patients were treatment-naive and 109 patients were treatment-experienced.

Results: In treatment-experienced patients, the most common reasons for the introduction of a $\mathrm{RAL}+\mathrm{PI} / \mathrm{r}$ regimen were virologic failure and impaired renal function (45 of 109 patients). In the treatment-naïve group kidney disease was the cause of the $\mathrm{RAL}+\mathrm{PI} / \mathrm{r}$ regimen in 3 of 17 participants. In treatment-experienced patients, $80 \%$ of individuals still were on $\mathrm{RAL}+\mathrm{PI} / \mathrm{r}$ treatment after 12 months, $65 \%$ after 24 months and $53 \%$ of subjects after 60 months. In both groups, the simplification of the antiretroviral regimen was the most common reason for discontinuation of $\mathrm{RAL}+\mathrm{PI} / \mathrm{r}$ based therapy. Conclusions: In antiretroviral-experienced patients the dual therapy based on $\mathrm{RAL}+\mathrm{PI} / \mathrm{s}$ is safe and effective. In antiretroviral-naïve patients the RAL + $\mathrm{PI} / \mathrm{r}$ regimen is rarely used in Poland.

Key words: HIV, dual therapy, raltegravir, protease inhibitors.

\section{Introduction}

Since combined antiretroviral therapy was introduced in 1996, huge progress has been made in this field. At the moment, over 30 antiretroviral drugs belonging to five main classes are available on the market, to limit HIV replication and progression of the disease [1].

Both Polish and international recommendations define the standard antiretroviral regimen as a combination of different drugs. The long expe-

\author{
Corresponding author: \\ Elżbieta Jabłonowska MD, \\ $\mathrm{PhD}$ \\ Clinic of Infectious Diseases \\ and Hepatology \\ Medical University of Lodz \\ $1 / 5$ Kniaziewicza St \\ 91-347 Lodz, Poland \\ Phone: +48606413757 \\ Fax: +48 606413757 \\ E-mail: elajablonowska@ \\ gmail.com
}


rience and established efficacy of regimens based on nucleoside and nucleotide reverse-transcriptase inhibitors justify their use as a main component of each drug combination [1-3]. However, antiretroviral regimens incorporating these drugs are not suitable for all patients. The main side effect of the nucleoside reverse-transcriptase inhibitors is mitochondrial toxicity, whereas the use of nucleotide reverse-transcriptase inhibitor has been associated with greater reductions in bone mineral density (osteopenia, osteoporosis) and renal toxicity [4-7]. In comparison to treatment-naïve HIV-infected patients, treatment-experienced patients are a difficult-to-treat group of subjects, in whom previous changes of drugs have narrowed the treatment options. Although great progress has been made in this field, new therapeutic options are still needed, and further collection of the experiences of the use of nonstandard therapies is extremely important.

The aim of this retrospective multicenter study was to present data on the use of dual therapy consisting of integrase inhibitor raltegravir (RAL) with ritonavir-boosted protease inhibitors $(\mathrm{PI} / \mathrm{r}$ ) in treatment-naïve and treatment-experienced HIV-infected patients.

\section{Material and methods}

The medical databases of six Polish HIV centers (Warsaw, Krakow, Wroclaw, Lodz, Szczecin, Chorzow) from January 2009 to December 2014 were analyzed for the use of combined antiretroviral treatment consisting of RAL and $\mathrm{PI} / \mathrm{r}$. During this period, a group of 126 patients receiving at least one dose of study drugs was enrolled in the study. No exclusion criteria were used to enable the evaluation of dual therapy in a real-world setting. Data were collected from the introduction of dual therapy based on $\mathrm{RAL}+\mathrm{PI} / \mathrm{r}$ to the last follow-up visit.

The authors addressed the following questions: What was the reason for the introduction of the dual therapy? What was the reason for discontinuation of the dual therapy? How long did the patients remain on this therapy?

The safety of therapy was measured as the number of patients discontinuing the therapy due to an adverse event.

In experienced patients, the efficacy was measured as the percentage of patients remaining free of therapeutic failure evaluated by a time to treatment failure algorithm. A Kaplan-Meier timeto-event method was used to determine the rate of "survival".

Missing data and discontinuation of therapy for any reason were considered as treatment failure.

The study was approved by the ethics committee of the Medical University of Lodz. Written informed consent was obtained from all participants of the study.

\section{Statistical analysis}

The Kaplan-Meier survival analysis was used, whereas stopping RAL $+\mathrm{PI} / \mathrm{r}$ treatment was taken as the primary end point.

\section{Results}

This retrospective study included 126 HIV-infected patients receiving $\mathrm{RAL}+\mathrm{PI} / \mathrm{r}$ therapy, of whom 17 patients were treatment-naive and 109 were treatment-experienced. The group comprised 92 males (76 in the treatment-experienced and 16 in the treatment-naive group) and 34 females ( 33 in the treatment-experienced and 1 in the treatment-naive group), with a median age of 42 years. The main route of HIV transmission in the study group was homosexual/bisexual contact. In the treatment-experienced group, before switching to $\mathrm{RAL}+\mathrm{PI} / \mathrm{r}, 19 \mathrm{pa}$ tients were on non-nucleoside reverse-transcriptase inhibitor based regimen, 11 on an integrase inhibitor based regimen and 79 on a PI based regimen.

The median duration of $\mathrm{RAL}+\mathrm{PI} / \mathrm{r}$ therapy was 60 weeks (mean: 87 weeks). The characteristics of the patients are presented in Table I.

\section{Reasons for introduction of $\mathrm{RAL}+\mathrm{PI} / \mathrm{r}$ treatment}

In treatment-experienced patients the most common reasons for introduction of the $\mathrm{RAL}+\mathrm{PI} / \mathrm{r}$ regimen were virologic failure and impaired renal function. For 14 treatment-naïve patients, the reasons for starting the $\mathrm{RAL}+\mathrm{PI} / \mathrm{r}$ regimen were not established, but in 3 participants it was kidney disease. All these reasons are presented in Table II.

\section{Reasons for discontinuation of $\mathrm{RAL}+\mathrm{PI} / \mathrm{r}$ treatment}

In 88 out of 126 patients, the treatment with $\mathrm{RAL}+\mathrm{PI} / \mathrm{r}$ was ongoing, while it had been ended in 38 patients (32 treatment-experienced patients and 6 treatment-naive patients). In both groups, the most common reason for discontinuation of $\mathrm{RAL}+\mathrm{Pl} / \mathrm{r}$ based therapy was the simplification of the antiretroviral regimen. All reasons given for discontinuation of the antiretroviral regimen are presented in Table III.

\section{Survival in treatment-naive and treatment-experienced patients}

Survival in the treatment-naive group is presented in Figure 1. In experienced patients, 80\% of subjects still were on $\mathrm{RAL}+\mathrm{Pl} / \mathrm{r}$ treatment after 12 months, $65 \%$ after 24 months and $53 \%$ of subjects after 60 months (Figure 2).

\section{Discussion}

Antiretroviral therapy has substantially improved the life expectancy of HIV-infected pa- 
Table I. Characteristics of study group

\begin{tabular}{|c|c|c|c|c|c|}
\hline \multicolumn{2}{|l|}{ Variable } & \multicolumn{2}{|c|}{ Treatment-experienced patients } & \multicolumn{2}{|c|}{ Treatment-naïve patients } \\
\hline & & $n$ & $\%$ & $n$ & $\%$ \\
\hline \multicolumn{2}{|l|}{ Men } & 76 & 69.7 & 16 & 94.1 \\
\hline \multirow{4}{*}{$\begin{array}{l}\text { Route of HIV } \\
\text { transmission }\end{array}$} & Intravenous drug users & 35 & 32.1 & 1 & 5.9 \\
\hline & Hetero & 22 & 20.2 & 3 & 17.6 \\
\hline & $\mathrm{Ho} / \mathrm{Bi}$ & 41 & 37.6 & 7 & 41.2 \\
\hline & Other/unknown & 11 & 10.1 & 6 & 35.3 \\
\hline \multirow[t]{5}{*}{ Regimens } & $\mathrm{RAL} / \mathrm{DRV} / \mathrm{r}$ & 65 & 59.5 & 15 & 88.2 \\
\hline & $\mathrm{RAL} / \mathrm{ATV} / \mathrm{r}$ & 22 & 20.2 & 1 & 5.9 \\
\hline & $\mathrm{RAL} / \mathrm{LPV} / \mathrm{r}$ & 17 & 15.6 & 0 & 0 \\
\hline & $\mathrm{RAL} / \mathrm{SQV} / \mathrm{r}$ & 5 & 4.6 & 1 & 5.9 \\
\hline & & Median & LQ-UQ & Median & LQ-UQ \\
\hline \multicolumn{2}{|c|}{ Age at the moment of HIV infection } & 33 & $26-40$ & 28 & $27-33$ \\
\hline \multicolumn{2}{|c|}{ CD4 at the moment of HIV infection } & 278 & $130-494$ & 334 & $243-495$ \\
\hline \multicolumn{2}{|l|}{ CD4 nadir } & 133 & $57-230$ & 318.5 & $140.5-387$ \\
\hline \multicolumn{2}{|c|}{ Age at the moment of introduction of PI/RAL } & 43 & $36-50$ & 32 & $29-39$ \\
\hline \multicolumn{2}{|c|}{$\begin{array}{l}\text { Duration of antiretroviral therapy before } \\
\text { the introduction of } \mathrm{PI} / \mathrm{Inl} \text { [weeks] }\end{array}$} & 62 & $40-129.4$ & 0 & \\
\hline \multicolumn{2}{|c|}{$\begin{array}{l}\text { Number of antiretroviral regimens before } \\
\text { the introduction of RAL/PI/r }\end{array}$} & 3 & $2-5$ & 0 & \\
\hline
\end{tabular}

Table II. Reasons for introduction of $\mathrm{RAL}+\mathrm{Pl} / \mathrm{r}$ treatment

\begin{tabular}{|c|c|c|c|c|}
\hline \multirow[t]{2}{*}{ Reason } & \multicolumn{2}{|c|}{$\begin{array}{l}\text { Treatment-experienced patients } \\
\qquad N=109\end{array}$} & \multicolumn{2}{|c|}{$\begin{array}{l}\text { Treatment-naïve patients } \\
\qquad N=17\end{array}$} \\
\hline & $n$ & $\%$ & $n$ & $\%$ \\
\hline Unknown & 11 & 10.1 & 14 & 82.4 \\
\hline Osteoporosis & 2 & 1.8 & 0 & 0 \\
\hline Renal dysfunction & 20 & 18.3 & 3 & 17.6 \\
\hline Gastrointestinal disorders & 7 & 6.4 & 0 & 0 \\
\hline Virologic failure & 25 & 22.9 & 0 & 0 \\
\hline Hematologic disorders & 5 & 4.6 & 0 & 0 \\
\hline Hypersensitivity & 3 & 2.8 & 0 & 0 \\
\hline Simplification of therapy & 12 & 11.0 & 0 & 0 \\
\hline Immunologic failure & 1 & 0.9 & 0 & 0 \\
\hline Lipoatrophia & 3 & 2.8 & 0 & 0 \\
\hline Lipid disorders & 5 & 4.6 & 0 & 0 \\
\hline Acidosis & 1 & 0.9 & 0 & 0 \\
\hline Polyneuropathy & 1 & 0.9 & 0 & 0 \\
\hline Drug interactions & 2 & 1.8 & 0 & 0 \\
\hline Intolerance & 11 & 10.1 & 0 & 0 \\
\hline
\end{tabular}


Table III. Reasons for discontinuation of RAL + PI/r treatment

\begin{tabular}{|c|c|c|c|c|}
\hline \multirow[t]{2}{*}{ Reason } & \multicolumn{2}{|c|}{$\begin{array}{l}\text { Treatment-experienced } \\
\qquad N=109\end{array}$} & \multicolumn{2}{|c|}{$\begin{array}{l}\text { First-line regimen } \\
\qquad N=17\end{array}$} \\
\hline & $n$ & $\%$ & $n$ & $\%$ \\
\hline Simplification of therapy & 16 & 14.7 & 3 & 17.6 \\
\hline Adherence/lost to follow up & 3 & 2.8 & 2 & 11.8 \\
\hline Kidney dysfunction & 0 & 0 & 1 & 5.9 \\
\hline Pancreatitis & 1 & 0.9 & 0 & 0 \\
\hline Bowel disorders & 1 & 0.9 & 0 & 0 \\
\hline Immunologic failure & 1 & 0.9 & 0 & 0 \\
\hline Rash & 1 & 0.9 & 0 & 0 \\
\hline Other & 3 & 2.8 & 0 & 0 \\
\hline Mental disorders & 1 & 0.9 & 0 & 0 \\
\hline $\begin{array}{l}\text { Death not associated with ARV } \\
\text { treatment }\end{array}$ & 2 & 1.8 & 0 & 0 \\
\hline $\begin{array}{l}\text { Lack of improvement of lipid } \\
\text { parameters and bilirubin }\end{array}$ & 1 & 0.9 & 0 & 0 \\
\hline Lipid disorders & 1 & 0.9 & 0 & 0 \\
\hline Virologic failure & 0 & 0 & 0 & 0 \\
\hline Myalgia & 1 & 0.9 & 0 & 0 \\
\hline Total & 32 & 29.4 & 6 & 35.3 \\
\hline
\end{tabular}

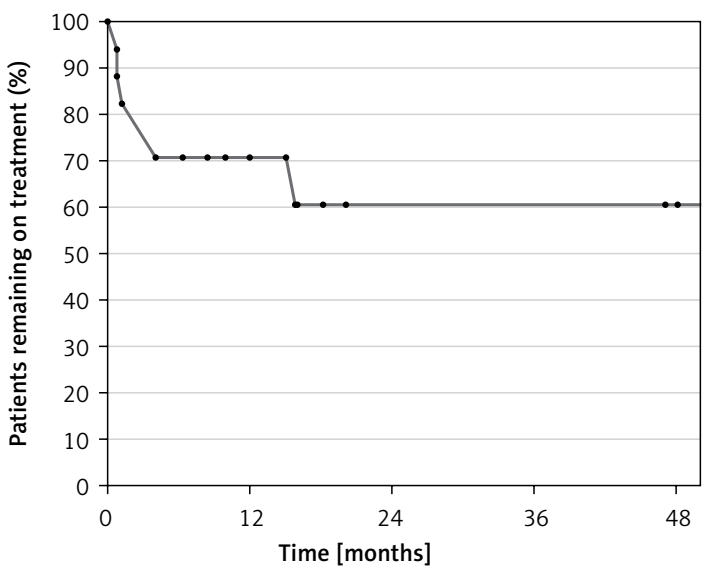

No. of patients

$$
17
$$

9

4

Figure 1. Survival with no treatment failure (treatment-naive group)

tients. Nowadays, opportunistic infections are observed far less frequently [8-10]. However, the antiretroviral therapy must be continued for the rest of the patient's life. Although current antiretroviral regimens are generally safe and well tolerated, they are not devoid of serious side effects $[5,7,11-14]$. Therefore the evaluation of available antiretroviral regimens provides new options for HIV-infected patients and allows their therapy to be individualized. The aim of the present work

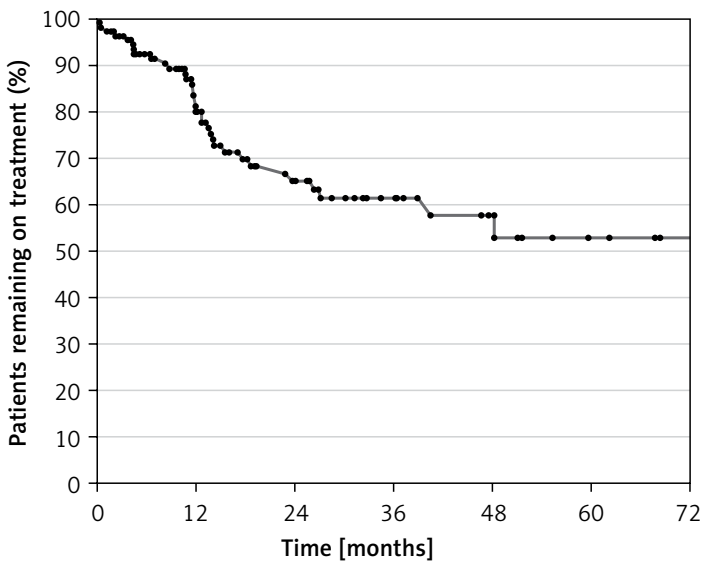

No. of patients

$\begin{array}{lllllll}109 & 70 & 41 & 23 & 13 & 8 & 4\end{array}$

Figure 2. Survival with no treatment failure (treatment-experienced group)

was to summarize the clinical experiences on raltegravir-containing regimens in combination with boosted protease inhibitors in patients from 6 Polish HIV treatment centers.

However, the Polish experience in the treatment of antiretroviral-naive patients with $\mathrm{RAL}+$ $\mathrm{PI} / \mathrm{r}$ is sparse, because such therapy has only been applied in 17 patients. It is worth noting that impaired renal function was given as the reason for the introduction of $\mathrm{RAL}+\mathrm{PI} / \mathrm{r}$ therapy in 3 patients, 
while no such information was given by the other patients. It is possible that the introduction of dual therapy in this group of patients is so rare due to the results of several studies which indicate that regimens containing $\mathrm{RAL}+\mathrm{Pl} / \mathrm{r}$ were not found to be as effective as treatment based on $\mathrm{PI}+2 \mathrm{NRTI} / \mathrm{r}$ [15-17]. Therefore, in Polish and international guidelines, dual therapy remains an alternative regimen in treatment-naïve HIV-patients [2, 3].

The majority of patients enrolled to this study (109) were administered dual therapy as consecutive treatment. In this group, $80 \%$ of patients still received $\mathrm{RAL}+\mathrm{PI} / \mathrm{r}$ after 12 months of treatment, while this number had fallen to $65 \%$ after 24 months. Our results are consistent with other studies concerning the safety and tolerability of the $\mathrm{RAL}+\mathrm{PI} / \mathrm{r}$ regimen in treatment-experienced patients. A study by Harness on virologically suppressed HIV patients who had been switched from a triple-drug regimen to RAL + ATV/r found that HIV viremia was still undetectable in $69.4 \%$ of patients 48 weeks after switching to the dual regimen [18]. In the SECOND-LINE study [15], where RAL + LPV/r was applied after failing the first-line regimen based on non-NRTI and $2 \mathrm{~N}(\mathrm{t}) \mathrm{RTI}, 80.4 \%$ of patients were found to have an HIV viral load below 200 copies $/ \mathrm{ml}$ after 96 weeks. It is important to note that, contrary to the SECOND-LINE study, the majority of patients in the present study received more antiretroviral regimens before the introduction $\mathrm{RAL} / \mathrm{PI} / \mathrm{r}$.

In conclusion, our findings indicate that in antiretroviral-experienced patients dual therapy based on RAL $+\mathrm{Pl} / \mathrm{r}$ is safe and effective. In antiretroviral-naïve patients the $\mathrm{RAL}+\mathrm{PI} / \mathrm{r}$ regimen is rarely used in Poland.

\section{Conflict of interest}

The authors declare no conflict of interest.

\section{References}

1. http://aidsinfo.nih.gov/contentfiles/lvguidelines/ AdultandAdolescentGL.pdf GftuoaaiH--iaaaDoHaHS.

2. http://www.eacsociety.org/guidelines/eacs-guidelines/ eacs-guidelines.html EgVN.

3. http://www.ptnaids.pl/attachments/article/20/Rekomendacje\%20PTN\%20AIDS\%202014.pdf ZonozHZPA.

4. Calza L, Trapani F, Tedeschi S, et al. Tenofovir-induced renal toxicity in $324 \mathrm{HIV}$-infected, antiretroviral-naive patients. Scand J Infect Dis 2011; 43: 656-60.

5. Mitra S, Priscilla R, Rajeev K, Sauradeep S, Rajkumar S, Cherian AO. Renal tubular dysfunction associated with tenofovir therapy. J Assoc Physicians India 2014; 62: 580-2.

6. Negredo E, Miro O, Rodriguez-Santiago B, et al. Improvement of mitochondrial toxicity in patients receiving a nucleoside reverse-transcriptase inhibitor-sparing strategy: results from the Multicenter Study with $\mathrm{Ne}$ virapine and Kaletra (MULTINEKA). Clin Infect Dis 2009; 49: 892-900.

7. Rasmussen TA, Jensen D, Tolstrup M, et al. Comparison of bone and renal effects in HIV-infected adults switch- ing to abacavir or tenofovir based therapy in a randomized trial. PLoS One 2012; 7: e32445.

8. Simon V, Ho DD, Abdool Karim Q. HIV/AIDS epidemiology, pathogenesis, prevention, and treatment. Lancet 2006; 368: 489-504.

9. Smith C, Sabin CA, Lundgren JD, et al. Factors associated with specific causes of death amongst HIV-positive individuals in the D:A:D Study. Aids 2010; 24: 1537-48.

10. Smith CJ, Ryom L, Weber R, et al. Trends in underlying causes of death in people with HIV from 1999 to 2011 (D:A:D): a multicohort collaboration. Lancet 2014; 384 241-8.

11. Kohler JJ, Hosseini SH, Hoying-Brandt A, et al. Tenofovir renal toxicity targets mitochondria of renal proximal tubules. Lab Invest 2009; 89: 513-9.

12. Margolis AM, Heverling H, Pham PA, Stolbach A. A review of the toxicity of HIV medications. J Med Toxicol 2014; 10: 26-39.

13. Rajesh R, Vidyasagar S, Patel N, ManjuVarghese. Safety aspects of antiretroviral therapy for management of HIV infection. J Basic Clin Pharm 2009; 1: 47-53.

14. Worm SW, Sabin C, Weber R, et al. Risk of myocardial infarction in patients with HIV infection exposed to specific individual antiretroviral drugs from the 3 major drug classes: the data collection on adverse events of anti-HIV drugs (D:A:D) study. J Infect Dis 2010; 201: 318-30.

15. Amin J, Boyd MA, Kumarasamy $\mathrm{N}$, et al. Raltegravir non-inferior to nucleoside based regimens in second-line therapy with lopinavir/ritonavir over 96 weeks: a randomised open label study for the treatment of HIV-1 infection. PLoS One 2015; 10: e0118228.

16. Bedimo RJ, Drechsler H, Jain M, et al. The RADAR study: week 48 safety and efficacy of RAltegravir combined with boosted DARunavir compared to tenofovir/emtricitabine combined with boosted darunavir in antiretroviral-naive patients. Impact on bone health. PLoS One 2014; 9: e106221.

17. Podzamczer D, Rozas N, Domingo P, et al. ACTG-HIV symptoms changes in patients switched to RPV/FTC/ TDF due to previous intolerance to CART. Interim analysis of the PRO-STR study. J Int AIDS Soc 2014; 17 (4 Suppl 3): 19814.

18. Lunzen JPA, Gatell J, Antinori A, et al. HARNESS study: ritonavir-boosted atazanavir (ATV/r)+raltegravir (RAL) switch study in virologically suppressed, HIV-1-infected patients. 20th International AIDS Conference; 2014 July 20-25, Melbourne, Australia. Poster LBPE19. http://pag. aids2014.org/PosterExhibition.aspx 